\title{
A TRADIÇÃO HISTÓRICA DOS ESTUDOS DE KEISHIKIMEISHI
}

Junko Ota

RESUMO: $\mathrm{O}$ artigo tem por fim traçar as diferentes consideraçōes teóricas tecidas em torno da categoria morfológica da língua japonesa denominada keishikimeishi. Começando por Yamada e Matsushita, que trataram especificamente do tema, as abordagens de cada teórico posterior são aqui analisadas sobretudo dos pontos de vista semântico e sintático, como uma forma de se compreender melhor o complexo funcionamento dos keishikimeishi que a língua japonesa possui.

ABSTRACT: This article aims to draw different theoretical considerations presented by grammarians on the morphological category of Japanese language, named keishikimeishi. Beginning with the grammarians like Yamada and Matsushita, who studied specifically the subject, approaches of late studies are here analysed by semantic and syntactic points of view, as a form to elucidate the complex functioning of Japanese language keishikimeishi.

PALAVRAS-CHAVE: Keishikimeishi; língua japonesa; semântica; sintaxe; gramática.

KEYWORDS: Keishikimeishi; Japanese language; semantics; syntax; grammar.

A categoria morfológica denominada keishikimeishi, cuja tradução literal significa "substantivo formal" ou "substantivo pró-forma", é no mínimo intrigante porque possui seu próprio conceito mas também se apresenta como um item gramatical. Foi a partir dessa observação que decidi estudar o tema referente ao keishikimeishi, sua posição dentro da gramática japonesa, as definições teóricas, e análise de alguns dos mais 
representativos, como koto e mono'. Neste artigo, destacarei as principais teorias concernentes ao keishikimeishi que a história da gramática da língua japonesa conheceu, desde Yamada até os tempos mais recentes.

\section{Consideraçōes de Yamada Yoshio sobre "Substantivos Especiais" (1908)}

Yamada foi um gramático que consolidou sua própria teoria gramatical, baseada nas características da língua japonesa, seguindo a teoria de Fujitani Nariakira e também observando as teorias ocidentais sobre gramática, psicologia e lógica. É considerado, portanto, fundador da base da gramática japonesa moderna. No seu primeiro livro, Nihon Bunpôron (1908), Yamada classifica as lexias da língua japonesa de acordo com o parâmetro funcional que apresentamos a seguir:
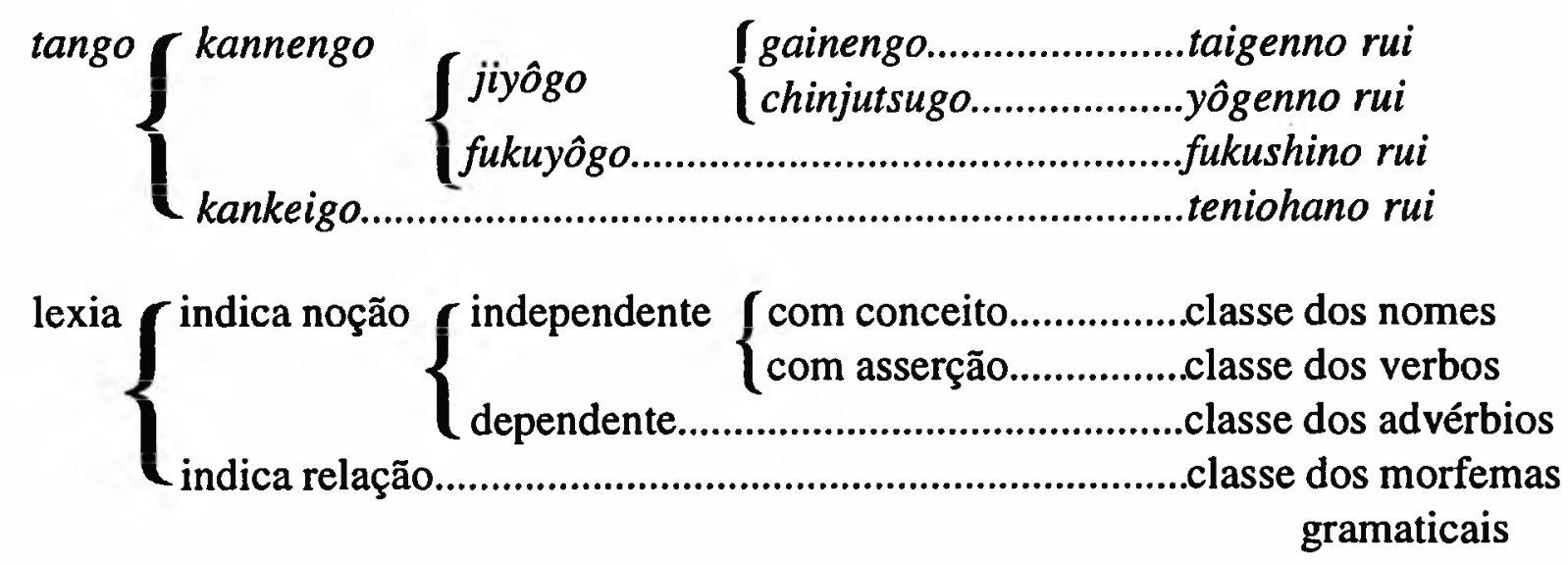

Levando em consideração os referentes das lexias, Yamada classifica-as em:

a) Kannengo, que expressam noção, $\mathrm{e}$

b) Kankeigo, que auxiliam os kannengo, indicando a relação entre os outros componentes da frase.

Dentro das lexias com noção, kannengo, o teórico distingue os constituintes oracionais independentes (jiyôgo) - como nomes, verbos e adjetivos - dos constituintes dependentes (fukuyôgo) - advérbios.

Dentre as lexias autônomas, jiyôgo, Yamada destaca os gainengo, que representam um conceito e correspondem a nomes, e outras que possuem a força da asserção, chinjutsugo, como os verbos e os adjetivos formadores de predicado. Como a terminologia a que Yamada recorreu não era comum na época, ele explica que "lexia com conceito" (gainengo) equivale a nome, taigen, até então utilizado para denominar lexias inflexíveis, e "lexia com noção de asserção" (chinjutsugo), é "formadora de predicado", yôgen, nome dado até então a lexias flexíveis. Yamada adota, dessa maneira, os nomes correntes na época, porém atribuindo-lhes significados diferentes dos que as

1. O presente artigo, que trata especificamente do histórico das definições de keishikimeishi dentro da gramática japonesa, faz parte da tese de doutoramento apresentada em 1996, junto ao Departamento de Lingüística da Faculdade de Filosofia, Letras e Ciências Humanas da USP. 
terminologias designavam até então. Taigen e yôgen são termos provenientes do Confucionismo, da linha Sôgaku². Embora Suzuki Akira, no período Edo, anterior a Meiji, tenha utilizado a terminologia taigen tal como define Yamada, ou seja "a expressão lingüística de um conceito", os teóricos posteriores a Suzuki, do início do período Meiji, tomaram-no meramente como lexias sem flexão, em oposição a yôgen, lexias flexíveis. Dessa maneira, incluíram dentro da classe de taigen não só os substantivos, mas também os advérbios, as conjunções e até mesmo as interjeições, por não serem flexíveis. Essas considerações foram avaliadas como errôneas por Yamada (1908:97).

O taigen, para Yamada, é a expressão lingüística de um conceito, que representa o fato ou as coisas consideradas como existentes. Suas características são distintas de acordo com a função, forma e relação que assume dentro da frase. Sintaticamente, um taigen pode constituir sujeito, ou fazer parte do predicado, dos complementos verbal e nominal. Quanto à forma, é sempre inflexível, independentemente da função sintática desempenhada. Sua relação com outras lexias é indicada mediante o auxílio dos morfemas de caso, tais como ga de sujeito, no de genitivo, to de companhia, $e$ de direção, yori de comparação, kara de procedência, $n i$ de objeto indireto, locativo ou agente da passiva e outros.

O taigen pode ser dividido em três subgrupos. Se expressa diretamente um conceito, será um nome propriamente dito (jisshitsu taigen) ou um substantivo (meishi); se expressa indiretamente um conceito, será nome apenas formalmente (keishiki taigen), correspondendo a pronomes e numerais. O nome keishiki-taigen não tem relação com o nosso objeto de estudo. Expomos a seguir o quadro de taigen e seus subgrupos segundo Yamada:

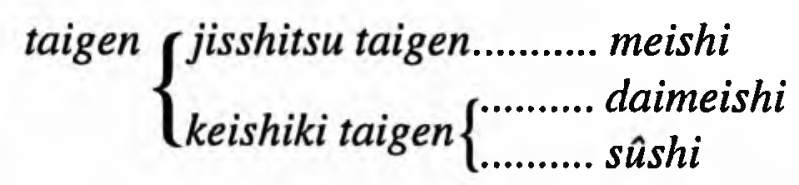

nome

$$
\left\{\begin{array}{l}
\text { nome propriamente dito.... substantivo } \\
\text { nome formal }\left\{\begin{array}{l}
\text {.................. pronome } \\
\text {................ numeral }
\end{array}\right.
\end{array}\right.
$$

O substantivo (meishi) foi considerado por Yamada uma representação direta de um conceito, que pode ser imaginário, idealizado, concreto ou abstrato, físico ou metafísico. Qualquer lexia, desde que seu conceito seja considerado objeto do pensamento, assume a categoria de substantivo.

2. Sôgaku é uma corrente do Confucionismo, cuja teoria foi sistematizada no período da dinastia Sung, na China. No Japão, é chamado também Shushigaku, adotado no período Edo como estudo oficial do governo Bakufu. O princípio de tai e yô ou yû (taiyûshisô) refere-se ao binômio substância/seu funcionamento, princípio/sua aplicação na prática, principal/subordinado. Na poética de renga e haikai, tai se refere a tipos de palavras relativas a montanha, lago, lugar, e yô se refere a coisas anexas a tai. Por exemplo, entre as palavras relativas à montanha, "colina, pico, cume, base da montanha" são consideradas tai, enquanto que "ponte suspensa, queda d'água, árvores, choupana de carvāo" são yô, havendo restrições de uso na composiçāo poética (Kokugo Daijiten). 
Dentro da categoria dos substantivos (meishi), Yamada observa, num subcapítulo intitulado "Os substantivos que requerem atenção especial" (1908:183-7), a existência de um número apreciável de substantivos, que alguns gramáticos consideram erroneamente como advérbios (fukushi), conjunções (setsuzokushi) ou sufixos (setsuji). Esses substantivos apresentam uma das seguintes características:

Ichiwa sono igi sukoburu kôhannishite, tandokunitewa ikanaru iginarukao shisaini hosokushigatakimade miyuru mononari. Ichiwa jibutsuno aidano kankeio chûshôtekini arawaseru mononari (Yamada: 1908:183).

a) possuem um "sentido muito amplo", dificultando sua apreensão quando se encontram isolados, ou

b) expressam de maneira abstrata "as relações dos fatos ou das coisas entre si"

Passaremos a detalhar, em seguida, esses dois itens apontados como características de "substantivos que requerem atenção especial", segundo Yamada.

a) Os substantivos portadores de "sentido amplo" são divididos em quatro tipos:

- os que designam causa ou motivo - yue, tame "causa";

- os que designam universalidade - toki "tempo, quando" aida "intervalo, durante, enquanto", tokoro "lugar, momento", koto "fato, ato", mono "coisa, objeto";

- os que designam intensidade - hodo, kurai "grau", koro "por volta de";

- os que designam enumeração - jô "item" e ken "caso".

Todos expressam conceitos e são passíveis de desempenhar funções de sujeito, de complemento verbal ou adjunto adverbial da oração, tais como outros substantivos, exceto pelo fato de, dada a amplitude de seu campo semântico, requererem um elemento que especifique seu sentido. Mas ao mesmo tempo em que afirma isso, diz Yamada que, em alguns casos, são empregados isoladamente, sem modificador (Yamada: 1908:184).

O gramático cita alguns exemplos desses substantivos, com e sem o elemento que os modifique:

Koro-shimo aki- no nagazuki- no. época - exatamente- outono - GEN.- mês longo ( $9^{\circ}$ mês) - AFIRMAÇÃo

"A época era exatamente de outono, nono mês."

Kono koro- no sora- no keshiki [...].

esta- época - GEN.- céu- GEN. - paisagem

"A paisagem do céu desta época [...]."

Yo- no akuru koro okiidete, [...]

noite- SUJ. - amanhecer- hora - levantou-se e,

"levantando na hora do amanhecer, [...]"

Genroku jûnen- goro okoritaru.

Genroku (nome de era) - 10 anos- por volta de - aconteceu

"Aconteceu por volta do ano dez da era Genroku." 
O teórico afirma que, quando uma oração modifica ${ }^{3}$ um certo substantivo, o conjunto [modificador e substantivo modificado] desempenha o papel de um nome. A importância semântica da oração modificadora faz com que o substantivo modificado pareça uma conjunção, no meio de duas orações. E quando uma só lexia constitui o modificador, o substantivo modificado se afigura como um sufixo. Em ambos os casos, afirma Yamada, mesmo quando o elemento modificado se parece com conjunção ou sufixo, continua sendo um nome.

b) "A relação recíproca entre os fatos e as coisas" é expressa pelos seguintes substantivos, concernentes ao espaço e tempo:

- mae "frente", ushiro "atrás", ue "em cima", naka "dentro", shita "em baixo", hidari "esquerda" migi "direita" que marcam a relação espacial;

- saki "antes", nochi "após", hajime "começo", naka "meio" e owari "fim", que indicam a relação temporal.

Tais substantivos, precedidos de outros substantivos com conceito, fazem destes um ponto de partida para indicar a direção, posição, limite ou área, com o auxílio dos morfemas yori, kara, indicadoras de ponto de partida. Nos exemplos a seguir, sublinhamos todo o sintagma nominal, destacando o substantivo modificado em negrito:

Hana-yori hoka- ni shiru mono- mo nashi.

flor- de - exceto - AFIRMAÇÃO - saber - pessoas- nem- nāo há

"Além de flores, nem há quem saiba"

Koko- kara nishi- e- wa ikubekarazu.

aqui- P. PARTIDA- oeste- DIREÇÃO-TÓPICO - não deve ir "É proibido ir a partir daqui para o oeste"

Kashiko- vori minami- wa hito- no ryô- nari. lá- P. PARTIDA - sul- TÓPICO- pessoa- GENITIVO - domínio- AFIRM. "O lado sul a partir de lá (daquela região) é do domínio de outra pessoa"

Há também exemplos desses substantivos modificados que, juntamente com outros morfemas no de genitivo e ga de sujeito, formam expressões que indicam tempo, espaço ou direção. Ex.:

Koyama- no ue- ni taie- ari. pequena montanha-GEN.- cima- LOC.- arrozais e casas- há "Sobre a pequena montanha, há casas e arrozais"

$\underline{\text { Kyô- }}$ no uchi- ni iku.

hoje- GEN.- dentro- LOC.- vou

"Vou (dentro de hoje) ainda hoje"

3. Estamos empregando a palavra "modificar" como tradução de shûshokusuru, assim como "modificador" para tradução de rentai-shûshoku-setsu. Esta terminologia designa todo e qualquer tipo de elementos dependentes do núcleo ou cabeça do sintagma nominal. 
Hako-no naka-ni mitsu- o takuwau.

caixa- GEN.- dentro- LOC.- mel- O.D.- armazena

"Armazena-se o mel dentro da caixa."

Shuttatsu- no mae- no yôi.

partida- GEN.- antes- GEN.- preparativos

"preparativos de antes da partida".

Segundo Yamada, os substantivos que indicam relação são empregados para expressar lugar, direção etc. Por corresponder, na concepção da gramática ocidental, aos advérbios de lugar e tempo, muitos gramáticos consideram a locução formada por substantivos e morfemas indicadores de caso como sendo advérbio, afirma Yamada. Adverte, porém, que não se deve jamais considerar essa locução como advérbio em japonês, uma vez que se trata de substantivo e morfema.

Em seu livro editado posteriormente (1936), no capítulo sobre uso das lexias, e especificamente sobre a modificação nominal (rentaikaku) ${ }^{4}$, Yamada faz uma observação referente aos substantivos que não constituem uma oração junto com os elementos do complemento nominal.

Exemplificando, o sintagma nominal gakkôe iku kodomo, "a criança que vai à escola", pressupõe a estrutura frasal [sujeito/predicado] kodomoga/gakkôe iku "a criança/ vai à escola". justamente porque o núcleo do sintagma kodomo "criança" pode constituir sujeito da ação expressa pelo modificador gakkôe iku "vai à escola" A análise das relações entre o modificador e o núcleo do sintagma nominal mostra que é comum o segundo ser sujeito da ação ou estado expresso no modificador. Pode ser, também, objeto direto, complemento verbal de lugar, além de exercer outras funções. É possível visualizar essas características no seguinte esquema:
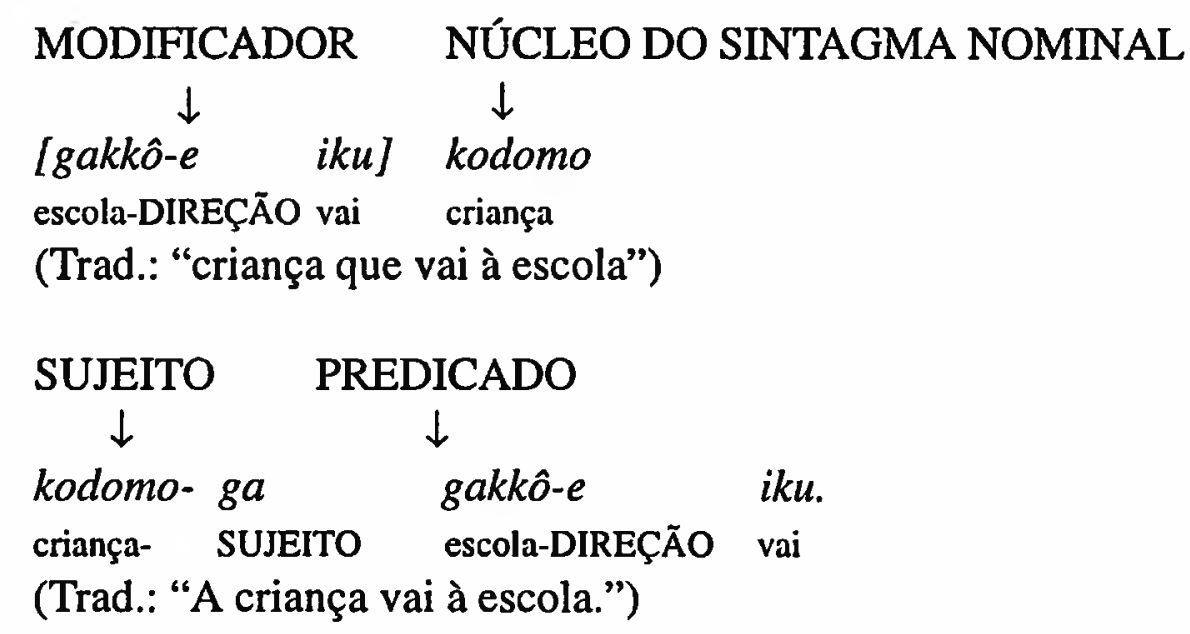

Outras construções de modificação nominal também pressupõem as estruturas [objeto direto/verbo do predicado], [complemento verbal de instrumento ou de lugar/ verbo do predicado]:

4. Rentaikaku refere-se à função exercida pelo modificador em relação ao substantivo modificado. 
[kodomo-ga kaku] e

criança-SUJ. pinta desenho

"o desenho que a criança pinta"

kodomo-ga e- o kaku

criança- SUJ. desenho- O.D. pinta

"a criança pinta o desenho"

[e- o kaku] heya

desenho-O.D. pinta quarto

"o quarto onde se pinta o desenho"

heya-de $\quad e$ - o kaku

quarto-LUGAR desenho-O.D. pinta

"Pinta-se o desenho no quarto"

Há, porém, núcleos de sintagma que não pressupõem tal construção e que, na opinião de Yamada, indicam tempo, lugar ou causa (1936:765-7):

a) hodo, nochi, ue, yue, aida, naka, tame - "por volta de", "depois" "além de", "por causa de", enquanto", "durante", "finalidade, causa"

b) tokoro, mono, koto, kan, jô - "lugar", "coisa", "fato", "durante", "portanto"

Essas lexias, portadoras do valor semântico de tempo, lugar, causa, coincidem com as "palavras que requerem atenção especial", comentadas na sua obra de 1908.

O tratamento semântico-sintático dessas lexias e sua relação com modificadores, comparado com outros substantivos não especiais, só será retomado posteriormente, por Teramura Hideo (1974), embora este não cite Yamada nas suas considerações referentes a essas construções. Teramura chama tais construções de "relação endocêntrica (uchino kankei)" e "relação exocêntrica (sotono kankei)."

Yamada afirma mais de uma vez nesse capítulo o caráter complexo dessas lexias: do ponto de vista semântico, são consideradas secundárias, porque o conteúdo semântico do modificador parece prevalecer sobre o conteúdo das lexias modificadas, e do ponto de vista sintático, são consideradas principais em relação ao modificador, subordinandoo, pois constituem núcleo do sintagma.

\section{Considerações de Matsushita Daizaburô sobre Keishikimeishi (1928)}

Foi o gramático Matsushita Daizaburô quem propôs a criação de um subgrupo de substantivos, dando-lhe o nome de keishikimeishi, literalmente "substantivo formal" ou "substantivo pró-forma". Chamando a atenção para suas peculiaridades, o teórico dá exemplos com koto "fato, ato", mono "pessoa", hazu "possibilidade, probabilidade", tame "finalidade, causa", mama "maneira, estado", no e outros, como verificaremos a seguir:

Tôfu- no koto- o bekkô- to iu tokoro- ga aru.

queijo de soja- GEN.- sobre- O.D.- casca de tartaruga- CIT. diz- lugar- SUJ.- há "Há lugares onde se chama o tôfu (queijo de soja) de 'casca de tartaruga' " 
Hitori- kurai- wa sanseisuru mono- mo arô. uma pessoa- ao menos- TÓP.- concorda- pessoa- também- deve haver "Deve haver pelo menos uma pessoa que vá concordar."

Sonna koto- o iu hazu- ga nai. esse tipo- fato- O.D.- dizer- possibilidade- SUJ.- não há "Não há possibilidade de ter dito tal coisa."

Sukoshi- wa kodomo-no tame- o kangaeru-ga ii. um pouco- TÓP.- criança- GEN.- bem- O.D.- pensar- SUJ.- bom "É bom que pense um pouco no bem das crianças."

Omotta mama- o kaku.

pensar- maneira- O.D.- escrever

"Escrever da maneira como vem à cabeça."

Ii no- ga aru.

boa- coisa- SUJ.- há

"Tem uma coisa boa."

Matsushita posiciona o keishikimeishi entre os quatro subgrupos de substantivos, que apresentamos a seguir:

- honmeishi "substantivos propriamente ditos", como hito "pessoa", ie "casa", kokoro "alma";

- daimeishi "pronomes" como ware "eu", kore "isto";

- miteimeishi "substantivos indefinidos" como dare "quem", nani "o quê";

- keishikimeishi "substantivos formais", comomono "pessoa" e ra que indica pluralidade.

Matsushita define os substantivos como aqueles que expressam o conceito, e dentro de seus subgrupos, apresenta os keishikimeishi como sendo substantivos que só possuem um significado formal e que carecem de um significado substancial "Keishikimeishiwa keishikiteki igibakaride jisshitsuteki igio kaku meishidearu" (1928:24).

O gramático situa o keishikimeishi dentro do seguinte quadro:

Substantivo \begin{tabular}{ll|l} 
com significado substancial & $\begin{array}{l}\text { com referente definido e fixo: } \\
\text { Substantivo propriamente dito } \\
\text { (ie "casa", kokoro "alma") } \\
\text { com significado definido } \\
\text { provisoriamente: } \\
\text { Pronome (ware "eu", }\end{array}$ \\
& $\begin{array}{l}\text { com significado indefinido: } \\
\text { Substantivo indefinido } \\
\text { (dare "quem", nani "o que") }\end{array}$ \\
sem significado substancial & $\begin{array}{l}\text { keishikimeishi [mono "pessoa", ra } \\
\text { (plural) }]\end{array}$
\end{tabular}


Sem o significado substancial, o keishikimeishi depende do conteúdo do modificador que se torna substancial semanticamente, dentro do sintagma. Por exemplo, a oração:

\section{Mono- wa kobamazu, \\ (pessoa) - TóPICO- não se recusa \\ "Não se recusam (pessoas)"}

em japonês, é desprovida de sentido, ou melhor, é de sentido incompleto, porque é empregado o keishikimeishi mono "pessoa" sem o modificador. Para ter sentido completo, a oração deve ser como a seguinte:

\section{Kuru mono- wa kobamazu.}

vem- pessoa- TÓPICO- não recusa

"Não se recusam as pessoas que vêm"

No exemplo acima, kuru "(que) vem" completa o significado do keishikimeishi mono "pessoa"

Os keishikimeishi se dividem em dois tipos, segundo a concepção de Matsushita:

a) os modificados pelas "palavras ou locuções que se ligam a nomes" rentaigo, são:

- mono "pessoa", koto "fato, ato" no, wake "razão", hazu "possibilidade", kata "pessoa", yatsu "pessoa", hô* "direção" tame "finalidade, causa" tokoro "lugar, momento", yuen "motivo" uchi "dentro, enquanto", mama "estado, maneira", yoshi "causa", gi "referência", kasho "parte", ken "caso", jin "pessoa", muki "voltado para", tochi "companheiro", dôshi* "companheiro", bun "parte", bu "tipo", me "situação" take "suficiente, apenas", hen "proximidade" setsu "ocasião" sai "ocasião", dan "momento", migiri "ocasião" tsudo "toda vez", tei "estado", yô "aspecto" tabi "ocasião", fû "estilo", tôri "jeito", sei* "causa" (Os assinalados com asterisco são de uso próprio da linguagem falada) (Matsushita: 1928:241-2)

Matsushita afirma que hô, dôshi e sei são formas próprias da linguagem falada, mas acreditamos que hoje elas são também empregadas na linguagem escrita.

Tais lexias são empregadas, acompanhadas pelas palavras que as antecedem, os rentaigo, constituídos de substantivo acompanhado de morfemas indicadores do caso genitivo no ou ga. Outros elementos que podem modificar os keishikimeishi são os verbos e adjetivos em flexão própria para se ligar a nomes ${ }^{7}$ segundo Matsushita. Ele cita os exemplos de rentaigo:

5. Os keishikimeishi kata e yatsu são formas de tratamento que se referem à "pessoa". Kata é usado como forma de respeito, referindo-se à segunda ou terceira pessoa, e imprime uma certa "distância" entre o falante e a pessoa referida, que se traduz como sinal de respeito. Opõe-se a kata o keishikimeishi yatsu, imprimindo "proximidade", é a forma que denota intimidade em relação à pessoa referida, quando há relação afetiva entre o falante e a pessoa referida, mas adquire tom pejorativo quando se trata de uma relação não afetiva.

6. Cf. nota anterior.

7. O nome da flexão é rentai-kei, literalmente, "forma com que se liga ao nome" 
- Tôkyố-no mono "gente de Tóquio", onde o rentaigo é constituído de substantivo (Tôkyô) e morfema de genitivo no.

- kuru mono "gente que vem", com rentaigo constituído de verbo kuru "vir".

- kono mono "esta pessoa", com rentaigo constituído de adjetivo demonstrativo kono "este"

Tais keishikimeishi designam a espécie à qual pertencem os fatos e coisas, podendo, portanto, ser chamados de "keishikimeishi indicadores de espécie" (jiruino keishikimeishi), conforme o teórico.

b) o segundo tipo de keishikimeishi é definido por Matsushita como aquele utilizado ao lado dos nomes, à sua direita, ou seja, posposto aos nomes. São eles:

nado, nazo, nando, nanka "por exemplo", tô "e assim por diante"

Todos esses são keishikimeishi que expressam exemplificação, segundo Matsushita, que não os considera morfemas, pelo fato de ocorrerem após os outros morfemas, como apresentamos a seguir:

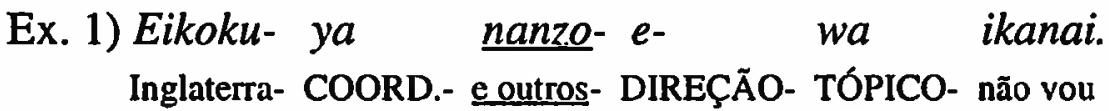
"(A países como) a Inglaterra (e outros), não vou."
Ex. 2) Sake- dano nanzo nonde-wa ikenai. saquê- COORD.- e outros- tomar- ÊNFASE- não pode "Não pode tomar saquê e outras coisas."

Ex. 3) Kôhii- ka nanka nomitai.

café- ou- alguma coisa- quero tomar

"Quero tomar café ou (alguma) outra coisa."

Apesar da afirmação de Matsushita, acreditamos que essas lexias destacadas no item b) apresentam as características de morfemas (joshi) e não keishikimeishi, pois há morfemas pospostos a outros, como é o caso de "morfemas de ênfase", fukujoshi, chamados também de "morfemas de destaque", toritatejoshi. A utilização de nanzo no exemplo 1) Eikoku nanzo... "por exemplo, Inglaterra e outros..." leva-nos a interpretálo como exercendo a função de destacar o substantivo Eikoku "Inglaterra", a mesma função exercida pelos morfemas de destaque, toritatejoshi.

Matsushita considera, em especial koto, mono e no, "os mais representativos da categoria de keishikimeishi", estudando-os detalhadamente. Ele define, classifica e exemplifica mono da seguinte maneira:

"Mono 者 significa "pessoa" enquanto keishikimeishi, contrastando com mono 物 "coisa/objeto", que é substantivo propriamente dito, honmeishi"

a) Designa "pessoa". Ex.:

$\begin{aligned} & \text { Ôboseru } \\ & \text { candidataram-se- }\end{aligned}$ pessoas-
"Sanahada
muito-


b) Designa "coisa, objeto" (jibutsu). Ex.:

Shôjin- no konomu tokoro- no mono- wa riroku-nari. pessoas mesquinhas- GEN. gostar- lugar- GEN.- coisa- TÓP.- lucro- é "(A coisa) O que as pessoas mesquinhas gostam são os lucros."

Kanata- ni utsukushiki mono ari. lá- LOC.- bonito- coisa- há

"Há coisas bonitas lá."

c) Designa casos, eventos, como "coisas". Ex.:

Hôkô- hodo tsuraki mono- wa araji. aprendizagem- como- difícil- coisa- TÓPICO- não há "Não há coisa tão difícil como a aprendizagem."

Sumajiki mono- wa miyazukae. enfadonho- coisa- TóP.- serviço do governo "(A coisa) enfadonha é estar a serviço da corte/do governo"

d) Expressa ordem ou determinação, ou seja, o resultado natural a que se chega através da intenção (ishiteki tôzen - meirei, kesshin - o arawasu). Ex.:

Shirazaru koto- wa kiku- mono- zo. não sabe- coisa- TÓPICO- perguntar- coisa- ÊNFASE "O que não se sabe, deve-se perguntar, viu?"

Uketemiru mon(o) $)^{8}$ da- nâ. Anna yatsu-ga kyûdaishita-ze. prestar- coisa- AFIRM. INTERJ. aquele- sujeito- SUJ.- passou- INTERJ. "(Realmente) vale a pena prestar (o exame). Até ele passou de ano!"

e) Expressa caráter, tendência natural. Ex.:

Atsui atsui iu- na. Natsu-wa atsui mono- da. está quente- está quente- dizer- PROIBIÇÃO. verão- TÓP.- quente- coisa- AFIRM. "Não fique repetindo que está quente. O verão é quente mesmo."

f) Expressa motivo, em tom apelativo, para justificar a conseqüência inevitável. Ex.:

Namakerunda- mono, rakudaisuru- sa.

é que está preguiçoso- é que- ser reprovado- EXCLAMAÇÃo

"É claro que ia ser reprovado, também. pudera, não estudava!"

(Matsushita: 1928:242-3)

O teórico não explicita o significado dos ideogramas mencionados anteriormente, distinguindo um do outro, considerando um (者) como keishikimeishi e outro (物) como substantivo propriamente dito, hoje interpretados como "pessoa" e "coisa" respectivamente. Porém, a classificação dos referentes de mono que Matsushita apresenta não está de acordo com a definição de mono na acepção única de "pessoa". o que nos

8. Mono, na língua coloquial e situado na parte predicativa, torna-se freqüentemente mon. 
faz supor que a acepção que temos hoje não se aplica para compreendermos o uso das lexias empregadas há quase 70 anos. Certamente, para o teórico, mono/者significava muito mais do que "pessoa". Também para o dicionário de ideogramas chineses, Kanwa Chû Jiten, temos como definição de mono/者 : jinbutsu, koto, tokoro nadoo sashite iu "designa pessoa, fato, lugar e outros" (Kaizuka et alii: 1984: 876). Outra nota do mesmo dicionário assinala que mono/物 se refere a "todas as coisas existentes entre o céu e a terra", e também se refere a "fatos"; e que mono/者 se refere a "coisas específicas do mono/物 "(1984:684).

A afirmação sucinta de Matsushita, porém, não nos oferece dados suficientes para concluir se a distinção entre mono/ 者 e 物 baseia-se nas diferenças entre o geral e o particular apontadas no referido dicionário.

Além disso, Matsushita não escreve todos os exemplos citados comokeishikimeishi com o ideograma, escrevendo apenas o mono citado no exemplo do a) e no primeiro do b). O restante é grafado em fonogramas hiragana.

$\mathrm{Na}$ classificação das diferentes acepções de mono destacadas por Matsushita, observamos que de um lado encontramos seu significado enquanto conteúdo referencial de mono "pessoa, coisa, fato, caso, evento...", mas há também o sentido extra-referencial que mono atribui à frase toda (ordem, ênfase, apelo), como é o caso dos exemplos dos itens d) em diante. Se pensarmos com rigor na distinção entre o significado da lexia propriamente dita e o sentido que ela imprime à frase toda, faz-se necessário separar em níveis distintos os itens destacados em seu quadro de classificação.

A lexia koto é definida por Matsushita da seguinte maneira:

Koto-O koto, enquanto substantivo propriamente dito, escrito em ideograma 事, significa "fato" mas é diferente do keishikimeishi koto, escrito em fonogramas. Tratando-se de koto, keishikimeishi, é recomendável não escrever em ideograma (Matsushita: 1928:244).

Na afirmação de Matsushita, não se esclarece a diferença semântica entre o kotol substantivo propriamente dito e o kotolkeishikimeishi. Sua recomendação para que não escreva o keishikimeishi koto em ideograma está relacionada, certamente, ao fato de os ideogramas representarem idéias, conceitos ou conteúdos substanciais que os keishikimeishi não comportam. Acreditamos que a recomendação reflete a intenção de Matsushita de diferenciar, através da escrita, o koto substantivo propriamente dito e o koto keishikimeishi. Isso não quer dizer, todavia, que ele se proponha a diferenciar o substantivo propriamente dito e o keishikimeishi através da sua escrita em ideograma ou fonogramas, respectivamente, porque nas considerações referentes a mono, ele afirma distingüi-los através de ideogramas diferentes(embora na prática ele os escreva em um ideograma e em fonogramas).

Apresentamos a seguir os exemplos de koto segundo Matsushita:

a) Designa "assunto, fato, ato, coisa, acontecimento" (kotogarao sasu): Ame- ga futte deru koto- ga dekinai. chuva- SUJ.- chove e- sair- ato- COMPL. CAPACIDADE- não pode "Chove e (portanto) (o ato de) sair não é possível." 
b) Designa "experiência"(keiken):

Wakai toki- ni ooi- ni namaketa koto- ga aru. jovem- tempo- LOC.- muito- vadiei- experiência- SUJ.- há

"Quando era jovem, tive uma boa experiência de vadiagem"

c) Designa "caso"(baaio sasu):

Ie- ni iru koto- mo ari, irazaru koto- mo ari.

casa- LOC.- estar- caso- também- há- não estar- caso- também- há

"(Hácaso em que estou em casa, há caso em que não estou) Às vezes estou em casa, às vezes não estou".

d) Designa "significado"(igio sasu):

Tenmongaku-no koto- o seigaku- to- mo iu. astronomia- GEN.- fato- O.D.- ciência dos astros- CITAÇÃO- também- diz "Denomina-se a Astronomia também de "ciência dos astros""

e) Indica a problemática relacionada ao fato (soreni kansuru mondaio sasu):

Oya- no koto- o wasurenai.

pais- GEN.- fato- O.D.- não esquece

"Não se esquece (o $\underline{\text { fato }}$ ) dos pais." sasu):

f) Designa valor atribuído a alguma coisa (sono shikarito nasuni taru kachio

Nanimo sô okoru koto- wa nai.

nada- assim- ficar bravo- fato- TóP.- não há

"Não tem que fícar tão bravo assim."

g) Indica o nome para um conteúdo (sono jitsuni taishite sono nao sasu):

Aru koto- wa aru- ga honno sukoshi- da.

há- fato- TÓP.- há- CONECTIVO ADVERSATIVO- muito- pouco- AFIRM.

"(O fato de ter, tem...) Ter, tem, mas é bem pouco."

h) Indica uma teoria de outrem (taninno setsuo sasu):

Kasei- ni- wa dôbutsu-ga iru- to iu koto- da.

marte- LOC.- TÓP.- animais- SUJ.- há- CIT.- dizer- fato- AFIRM.

"Em Marte, dizem que há animais."

i) Expressa norma ou prescrição. Corresponde a beshi "deve" (ishiteki tôzen kihan - o arawasu. 'Beshi' no ini naru):

Tomodachi- wa erabu koto da- yo.

amigo- TÓPICO- escolher- fato- AFIRM.- ÊNFASE

"Os amigos, devem-se escolhê-los, viu?" (Os amigos, você deve escolher.)

Observamos que determinados empregos de koto - a exemplo do que ocorre com o item i - parecem imprimir sentido de prescrição à frase toda. Na consideração de Matsushita, porém, essa concepção não está clara, estando, portanto, no mesmo nível de outros empregos. 
Matsushita, ao traçar as características de keishikimeishi, baseia-se em critérios sintagmáticos e semânticos, como se observa a seguir:

a) Aspectos sintagmáticos:

- postula a ocorrência de keishikimeishi após o rentaigo (palavras ou locuções que se ligam a nomes) no caso do $1^{\circ}$. grupo, e a ocorrência após o substantivo no caso do $2^{\circ}$. grupo.

b) Aspectos semânticos:

- Matsushita estabelece o "conteúdo pró-forma e não substancial" do keishikimeishi, mas, ao mesmo tempo em que afirma isso, assegura que tais lexias expressam "conteúdos sutis" Matsushita assume uma postura valorativa quando diz que "isso é motivo de orgulho do povo japonês pois demonstra sinal da evolução lingüística" criticada posteriormente por Sakuma Kanae (1936/1966:75).

- na análise das características do conteúdo referencial do keishikimeishi, Matsushita afirma ainda que o $1^{\circ}$. grupo indica a categoria ou espécie de coisas e fatos (jibutsuno ruio shimesu), e que o $2^{\circ}$. grupo expressa a exemplificação.

\section{Considerações de Hashimoto Shinkichi sobre Keishikimeishi (1948)}

A contribuição de Hashimoto em relação à taxionomia da língua japonesa foi ter proposto, além das classes de palavras hoje adotadas dentro da gramática escolar, a divisão das lexias em autônomas e dependentes, isto é, as assim denominadas dokuritsugo e fuzokugo, elementos que, juntos, constituem uma "unidade sintática", bunsetsu. Uma unidade sintática é, para Hashimoto, marcada pela pausa anterior e posterior a ela, que se faz na atualização do enunciado. Uma lexia independente pode constituir uma unidade sintática por si só, ou juntamente com uma lexia dependente. Ao contrário, esta nunca constitui a unidade sintática por si só. A diferença entre os dois grupos se faz através da verificação da possibilidade ou não de se pronunciar entre pausas. Se há pausa, ter-seá uma lexia autônoma, se não, ter-se-á uma dependente. $O$ critério adotado por Hashimoto, portanto, é válido somente para o falante dotado de intuição lingüística do japonês, pois só ele saberia onde começa e termina uma palavra, e onde se pode inserir uma pausa.

Utilizando-se da terminologia existente desde as primeiras divisões taxionômicas do período Muromachi, shi e ji, Hashimoto designa "shi" o elemento autônomo e "ji" o elemento dependente:

"[...] daiisshu dainishuno betsuwa, soredakede zengoni kiremeo oite hatsuonsuru kotoga dekiruka (sunawachi dokuritsusuruka) inakaniyotte sadamarunodeatte, katachino uekaramo meiryôni kubetsudekirunodearu. Ima, daiisshuno goo shi, dainishuno goo jito nazukeyô.

[...] bunsetsukôseijôno seishitsuno chigainiyotte, gowa shito jitoni wakareru. Shiwa tandokude bunsetsuo kôseishiubeki monodeari, jiwa tsuneni shini tomonatte bunsetsuo kôseisuru monodearu" (Hashimoto: 1948/1968:45-6). 
“[...] A distinção entre o primeiro e o segundo tipo se define com a possibilidade ou não de pronunciá-los entre pausas anteriores e posteriores (ou melhor, se é independente ou năo) e se pode distinguir também pela forma. Denominaremos o primeiro tipo shi e o segundo $j i$.

[...] Dependendo da diferença da natureza com que constitui a unidade sintática, as lexias se dividem em shi e $j i$ (independente e dependente). A lexia independente é capaz de constituir por si só uma unidade sintática, e a dependente sempre a constitui acompanhando uma independente."

Observamos que, no estabelecimento das características funcionais dos keishikimeishi, Hashimoto leva em consideração dois aspectos: seu aspecto fonológico, ao se referir às pausas, e seu aspecto sintático, quando descreve sua constituição em unidade sintática.

Hashimoto estuda o grupo keishikimeishi no capítulo intitulado "nomes", taigen. Num subcapítulo, analisa os keishikimeishi koto "fato, ato", mono "pessoa, coisa", tokoro "lugar, momento", aida "intervalo/durante, enquanto", yue "causa", tame "finalidade, causa":

"Keishikimeishiwa meishitoshiteno hatarakio yûsuruga, sorejishinno yûsuru imiwa usuku, tsuneni sono jisshitsuo arawasubeki goga soreni tomonaumonodearu" (Hashimoto: 1959/ 1967:77).

"Os keishikimeishi desempenham o papel de substantivo, mas o significado que possuem é tênue, sendo assim acompanhados de termos que devem expressar sua substância"

Ainda segundo Hashimoto, alguns são empregados de maneira independente como substantivos, podendo ser considerados keishikimeishi, quando empregados em casos particulares. São as lexias ken "caso", kata "pessoa", bun "parte", hen "proximidade" muki "inclinação, tendência/voltado para", as quais diferem de outras por requererem um modificador nominal. Essas devem ser, portanto, consideradas especiais. Mas Hashimoto acrescenta que, sendo possível separar o modificador e keishikimeishi em unidades sintáticas distintas, não se pode considerar essas lexias como completamente dependentes.

Hashimoto distingue, dentre os keishikimeishi,

a) aqueles que são substantivos (meishi), $\mathrm{e}$

b) os que apresentam caráter adverbial (fukushiteki).

Exemplos de a): tokoro "lugar, momento", koto "fato, ato", mono "coisa, pessoa", toki "tempo/quando", koro "época, tempo", tame "finalidade, causa", wake "razão" yatsu "pessoa" em forma pejorativa, tabi "vez", aida "intervalo/durante, enquanto" yue "causa", hazu "probabilidade", ken "caso", jô "item", hodo "intensidade", kurai "grau" entre outros.

Exemplos de b): jô "item" setsu "ocasião" migiri "ocasião" tsudo "vez", hazu "probabilidade", ken "caso", bun "parte", hô "lado, direção", kata "lado, direção", hen "lado", muki "inclinação/voltado a", dôshi "companheiro", tokoro "lugar, momento", koto "fato, ato", mono "coisa, pessoa", toki "tempo/quando", koro "por volta de", entre outros. (Hashimoto: 1959/1967:77-9) 
Examinando os dois subgrupos de keishikimeishi propostos por Hashimoto, observamos lexias que fazem parte tanto dos substantivos, como dos que apresentam caráter adverbial. Entretanto a obra Nihon bunpôron "Teoria da gramática japonesa" (Hashimoto: 1959), constituída de anotações para as aulas que o teórico ministrava, não apresenta explicações a esse respeito. Talvez isso seja explicado pelos diferentes critérios que o teórico adotou para classificar os keishikimeishi: o primeiro, um critério morfológico, e o segundo, um critério sintático. A adoção de diferentes critérios, de um lado, faz-nos pensar que a metodologia adotada para classificação não era adequada, mas, por outro lado, explica a dificuldade que os teóricos tinham, e ainda têm, para sistematizar a classe de keishikimeishi.

Vale observar ainda que no e hodo, lexias consideradas keishikimeishi por muitos teóricos, pertencem, na concepção de Hashimoto, ao subgrupo dos morfemas que ele chama jun'yôji ou jun'yôjoshi, definidos como "morfemas que atribuem às partes precedentes a categoria de outra classe". Dentro do grupo de morfemas chamado jun 'yôji, o juntaijoshi é o que corresponde ao grupo de keishikimeishi concebido por Matsushita. O juntaijoshi, definido por Hashimoto como "morfemas que atribuem a categoria de nome às partes precedentes". é exemplificado pelos seguintes morfemas:

- no (Watashi-no- ga,

eu- $\quad$ coisa- SUJEITO

"a coisa de mim/o meu (na função de sujeito)"

$i k u-\underline{\text { no- }} o$ ),

ir- ato- O. DIRETO

"(o ato de) ir (na função de objeto direto)"

- hodo (mittsu-
$\begin{gathered}\text { hodo- } \\ \text { três- }\end{gathered}$
em torno de, por volta de- SUJEITO-
"ex torno de três é um bom número."

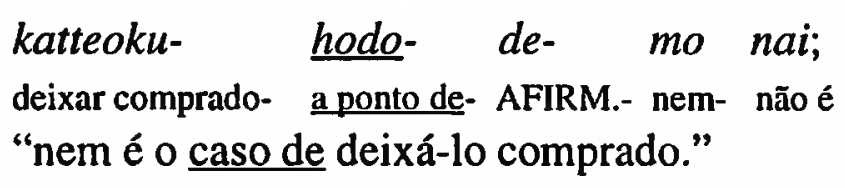

shimpaishita- hodo- no koto-mo nai,

fiquei preocupado- a ponto de- GENITIVO- fato- nem- não há

"(o fato nem chegou ao ponto de requerer minha preocupação) nem chegou ao ponto da minha preocupação."

imamade- hodo benkyôshinai)

agora-até- como- não estuda

"não estuda tanto quanto o fez até agora."

A preocupação de Hashimoto com as classificações de lexias em geral, a nosso ver, é de caráter sintagmático e morfológico, mas muito pouco voltada ao caráter semântico. De fato, Hashimoto parece ser o gramático que, entre os seus contemporâneos, menos levou em consideração as relações semânticas entre os constituintes da frase. 


\section{Considerações de Tokieda Motoki sobre Keishikimeishi (1950)}

Diferentemente de Yamada, que concebeu a língua como um conjunto de dois elementos - som e pensamento - que se unem para interação mútua (sôgô kankitekini ketsugôshita mono), Tokieda procurou ver a linguagem como a própria atividade física $\mathrm{e}$ psicológica do homem, isto é, a exteriorização de seu sentimento. Para Tokieda, a essência da linguagem está no processo psíquico através do qual o homem transforma o referente em signo lingüístico por intermédio dos sons ou da escrita. "Oh!" e "não". por exemplo, são expressōes diretas do sentimento do falante, enquanto que "surpresa" ou "negação" são expressões objetivas e abstratas do conteúdo do pensamento do falante, que resultaram do processo de abstração do sentimento. Os shi e ji diferem essencialmente nesse ponto.

Tal concepção levou o gramático a elaborar a "Teoria do Processo Lingüístico" (Gengo Kateisetsu), servindo-lhe de base para propor uma classificação binária das lexias japonesas em nocionais (shi) e relacionais (ji). Nocionais ou shi designam, conforme Tokieda, conceitos resultantes do processo de concretização do conteúdo referencial; e relacionais ou $j i$ são expressões da subjetividade do locutor com relação ao conteúdo proposicional. A oposição entre shi e ji fazia parte da teoria de Hashimoto, quando ele propôs a divisão das lexias em autônomas e dependentes, mas Tokieda parte de outro ponto de vista.

No capítulo sobre nocionais, shi, e no subcapítulo intitulado "Nomes e Substantivos", taigento meishi, da obra Nihon Bunpô Kôgohen (1950), Tokieda destaca grupos de lexias cuja inclusão entre os substantivos não considera apropriada:

Taigenno nakaniwa, iwayuru meishino nakani ireruniwa fusawashikunai monoga aru kotoo chûishinakereba naranai. [...] Honshoni oitewa, [...] meishito suruniwa fusawashikunaiga, aru kannen'o hyôgenshi, katsu gokeihenkao shinai monoo taigentoshita (Tokieda: 1950/1968: 70-1).

Entre os nomes, é preciso observar que se encontram alguns que não são adequados para serem incluídos dentro dos substantivos. [...] Neste livro, considerei 'nomes' os que não podem apropriadamente ser incluídos entre os substantivos, mas que expressam um determinado conceito e, além disso, não apresentam variação formal.

Na definição que acabamos de mencionar, Tokieda afirma que nomes, taigen, são os que não apresentam características próprias de substantivos, meishi. No entanto, no mesmo livro, no capítulo sobre o keishikimeishi e okeishikidôshi, as lexias que deveriam fazer parte de nomes (taigen) e não de substantivos são consideradas substantivos (meishi), contradizendo a afirmação anterior.

Questionando a afirmação de Matsushita de que os keishikimeishi possuem apenas a forma de substantivo, Tokieda afirma que eles também expressam um conceito:

Korerano goga, tanni meishitoshiteno ippanteki keishikishika motteinaito miru kotowa gimondeatte, yahari gotoshite aru gainen'o hyôgensuru monodearu kotowa machigainaidearôga, tada sono gainenga kiwamete chûshôteki keishikitekidearu tameni, tsuneni koreo hosokushi genteisuru shûshokugoo hitsuyôtosuru yôna meishidearutoiu hôga tekisetsudearu. [...] 
keishikimeishiga bunpôjô chûisarerunowa, sono gainen naiyôno mondaidewa naku, sorega tsuneni nanrano shûshokugoo tomonai, soreo fukumete hajimete shugonari, jutsugonarini tachiuru hidokuritsuseino meishidearuto iu tenni arunodearu (Tokieda: 1950/1968:90).

É duvidoso considerar-se que esse tipo de lexias só possui uma forma geral de substantivo. Provavelmente não há dúvidas de que os keishikimeishi são lexias que expressam conceito enquanto lexia, mas sendo seu conceito extremamente abstrato, é mais apropriado dizer que se trata de substantivos requerendo sempre um modificador que os complemente e os modifique. [...] Os keishikimeishi chamam-nos a atenção não em função do seu conteúdo semântico, mas porque, sendo um substantivo de caráter dependente, somente com a junção do modificador pode desempenhar a função de sujeito, ou de predicado.

Tokieda não chega a sistematizar os keishikimeishi como fizeram Yamada e Matsushita, mas arrola algumas lexias que conformam tal grupo:

Tabi "vez" hazu "probabilidade", tame "finalidade, causa" mama "maneira, estado", wake "razão", no, ori "ocasião" yô "estado, aspecto" koto "fato, ato" ue "sobre", yue "causa", kan, ken "caso", ten "ponto", ageku, mono "coisa, pessoa", tokoro "lugar, momento". yoshi "razão"

\section{Considerações de Sakuma Kanae sobre Kyûchakugo (1952)}

Abordando a problemática do keishikimeishi, Sakuma Kanae questiona a divisão das lexias japonesas em shi (lexias autônomas) e ji (lexias dependentes) proposta por Hashimoto (1948), classificação baseada no critério da dependência ou não das lexias de acordo com seu emprego na frase (cf. cap.3). Sakuma afirma haver lexias que, mesmo consideradas "autônomas" shi, desempenham uma função sintática somente quando acompanhadas de um modificador. $O$ emprego dessas lexias se assemelha ao das lexias dependentes, $j i$. Esse fato mostra que os limites entre shi e $j i$ não são tão claros como a lógica que divide o A e o não-A, o que constitui um ponto fraco na argumentação dos defensores da oposição entre os dois, afirma Sakuma (1952/1967:325).

Diante desse problema apresentado pelo keishikimeishi na divisão binária shi/ji, Sakuma resgata a concepção de jun'yô, (atribuição ou extensão do estatuto de uma classe de palavras ao elemento anteposto) apresentada por Hashimoto, segundo a qual há certas lexias dependentes que, ligando-se a uma outra, atribuem-lhe o estatuto de sua classe. Sakuma afirma que as lexias que ele chama de kyûchakugo possuem essa característica de atribuir ao segmento antecedente, ou seja, ao modificador, o caráter da classe de palavras a que pertencem. O que ocorre com os kyûchakugo, afirma ainda Sakuma, não é a mera atribuição do estatuto de uma classe de palavras ao modificador, pois eles, não possuindo um significado substancial, para serem complementados, ligamse a um modificador com um conteúdo semântico mais preciso.

De acordo com Sakuma, é grande a quantidade de lexias com tais características. Entre elas, há aquelas que são consideradas nomes (taigen), ou lexias autônomas, e outras consideradas lexias dependentes. Mesmo as consideradas autônomas, não os são totalmente, pois requerem uma outra lexia ou uma locução para sua complementação 
semântica. Tais lexias são chamadas por Sakuma de kyûchakugo "palavras aglutinantes ou adsorventes"

Os kyûchakugo, na concepção de Sakuma, não possuem um conteúdo semântico substancial, que interpretamos como um refencial extra-lingüístico específico. Para o teórico, as lexias chamadas keishikimeishi por Matsushita possuem todas as características do grupo de kyûchakugo. Do seu ponto de vista, ainda, os keishikimeishi são lexias nominalizadoras, que atribuem ao seu modificador a categoria de substantivo, portanto são "kyûchakugo de função nominal"

Na opinião de Sakuma, o keishikimeishi (exceto no) é considerado lexia autônoma, razão pela qual é incluído nos dicionários na categoria dos substantivos (meishi). Os keishikimeishi, porém, tendo desenvolvido a função de atribuir o estatuto de substantivo aos seus modificadores, não são lexias totalmente autônomas. Sakuma cita o exemplo:

Ex. Amerika- e ittekita mono- wa, daredemo sô iimasu.
Estados Unidos- DIR.- esteve- pessoa- TÓPICO- qualquer um- assim- diz
"Qualquer pessoa que já esteve nos Estados Unidos fala assim."

Neste exemplo, mono "pessoa" significa genericamente "pessoa que tem alguma qualificação" ou "pessoa especificada por Amerika-e ittekita" e constitui um kyûchakugo, que se aglutina ao segmento antecedente. Embora seja considerado um substantivo, não se pode construir frases como "mono fez tal coisa", ou "mono é assim", sendo necessário que esteja sempre acompanhado de expressões (lexias ou locuções) modificadoras. No exemplo apresentado, mono não pode dispensar o modificador Amerika e itte kita "que esteve nos Estados Unidos", donde se conclui que não pode ser considerada uma lexia autônoma, shi. Mas, considerá-lo lexia dependente, $j i$, tal como os morfemas e os auxiliares verbais (jodôshi e joshi), tampouco é adequado, afirma o teórico. Embora seja possível considerar a oposição entre lexias autônomas e dependentes, pensar que as questões referentes às lexias se resolvem com a simples dicotomia é uma posição equivocada, critica Sakuma. Sua crítica se aplica não só à teoria da oposição shi/ji proposta por Hashimoto, baseada na autonomia ou dependência das lexias para comporem as unidade sintáticas, mas também à concepção apresentada pela "Teoria do Processo Lingüístico" de Tokieda (1941), baseada no processo pelo qual passa a exteriorização de sentimento do falante.

Sakuma chama a atenção para o fato de que os kyûchakugo incluem elementos não somente com função nominal, mas também os com função adverbial e com função adjetiva. Os kyûchakugo de função nominal, comumente classificados como substantivos de designação genérica, são, segundo Sakuma, "lexias que apresentam um campo semântico não delimitado por si só, e por isso têm a necessidade de sofrer uma restrição por meio de um modificador" (sorejishinwa genteisareteinai aru shuno wakuo shimesu gode, sorewa yagate gentei [sôtei] o matteiru mononanodesu - Sakuma: 1952/1967:327). Essa caracterização é estendida a todos os kyûchakugo, mas é facilmente verificável sobretudo naqueles com função nominal.

Assim, o gramático enumera os kyûchakugo com funções diversas, dos quais citaremos apenas os com função nominal, divididos em 7 grupos e diferenciados de acordo com o que exprimem: 
1) os que exprimem "pessoa"

hito/hitotachi "pessoa/pessoas", kata/katagata "pessoa /pessoas (forma de respeito)", yatsu/yatsura "pessoa/ pessoas (forma depreciativa ou de intimidade), mono/ monodomo "pessoa/pessoas" etc.

2) os que exprimem objetos

mono "objeto", hô "lado", bun "parte" etc.

Mono é usado para "objeto", freqüentemente no sentido genérico, podendo ser substituído por yatsu.

3) os que exprimem fatos

koto "fato", hanashi "conversa, história", ten "ponto" etc.

4) os que exprimem eventos, estados

baai "caso", shimatsu "desfecho", yôsu, chôshi, moyô "estado, situação", arisama, zama, tei, teitaraku "estado (lastimável)" etc.

5) os que exprimem lugar

tokoro "lugar", atari, hen "por volta", kaiwai "vizinhanças, arredores" etc.

6) os que exprimem tempo

Formam freqüentemente uma oração adverbial, com ou sem o acompanhamento do morfema $n i$, podendo desempenhar função de conjunção. Entre esses, os seguintes keishikimeishi exercem função de sujeito:

toki "quando", uchi "enquanto", aida "durante", koro "tempo", jibun "época" saichû "enquanto" etc.

7) os que exprimem causa, motivo

$k i$ "intenção", tsumori "intenção" hazu "probabilidade" etc.

Além dos sete itens que acabamos de mencionar, Sakuma cita mais um, o "item dos que exprimem intensidade", definindo-os da seguinte maneira: "De função adverbial, ocasionalmente utilizados como nome. São freqüentemente considerados morfemas de ênfase, fukujoshi", sem contudo mencionar exemplos.

Os 67 kyûchakugo levantados por Sakuma, com função nominal, divididos em oito grupos, são acrescidos de outros, com funções adjetiva, adverbial e conectiva, referentes a tempo, condição e causa (seijônitsuiteno kyûchakugo; fukushiteki oyobi setsuzokutekina kyûchakugo; tokini kansuru kyûchakugo; jôken, riyûnitsuiteno kyûchakugo - Sakuma:1952/1967:321). Entre os kyûchakugo com função adjetiva, Sakuma cita tai (exprime volição), nai (exprime negação) e rashii (exprime aparência, suposição) que, devido à sua flexão semelhante à de adjetivo keiyôshi, quando ligados a um verbo, fazem com que esse passe a flexionar como adjetivo, como tabe-nai "não come" tabe-tai "quer comer" taberu-rashii "parece que come" Estes kyûchakugo com função adjetiva concebidos por Sakuma são considerados auxiliares verbais (jodôshi) pela maioria dos gramáticos.

Sakuma associa aos keishikimeishi apenas os kyûchakugo com função nominal. Outros kyûchakugo, porém, incluem também os keishikimeishi mencionados pelos 
teóricos antecedentes. São lexias incluídas dentro da categoria de keishikimeishi por alguns teóricos, mesmo que tais lexias nem sempre constituam sujeito. Elas fazem parte de locução ou oração adverbial, fato que provoca discussões em torno da própria definição da categoria keishikimeishi ou keishikitaigen.

Os kyûchakugo de função adverbial apresentados por Sakuma são:

- tôri "jeito", mama "estado", kurai "só", kuse, tame "para", "causa" etc.;

- toki(ni) "quando", tokoro(o, e, de) "no instante", koro "na época", sai(ni), ori(ni) "na ocasião", saichû "enquanto" totan(ni) "repentinamente" etc.

A proposta de Sakuma com criação da classe de kyûchakugo não chegou a ser adotada pela gramática japonesa. Contudo, é preciso considerar a pertinência de sua teoria, pois o autor dividiu as lexias, de acordo com a função sintática, em nominal, adjetiva e adverbial, destacando as de função nominal que assumem papel de sujeito.

Além disso, ele percebeu a ocorrência de jun'yô (atribuição ou extensão do estatuto de uma classe de palavras ao segmento anteposto) nas lexias não dependentes, o que ocasionou a proposição de uma nova classe, kyûchakugo, incluindo as lexias autônomas e dependentes. Concordamos com Morioka (1988:185) quando ele afirma o seguinte: "a concepção da classe de kyûchakugo como um grupo de lexias que têm por função atribuir o estatuto de classe de palavras ao modificador é bastante inovadora, se se considerar as definições dos teóricos precedentes, que até então limitavam a descrever os keishikimeishi como um elemento sempre complementado por modificador"

Não obstante, na nossa opinião, há também certos inconvenientes na classificação do teórico, porque ela abarca as lexias que são morfologicamente diferentes, ou seja, as flexíveis e as não-flexíveis (flexíveis: tai, nai, rashii-com função adjetiva; não-flexíveis: koto, mono - com função nominal).

A inclusão de elementos heterogêneos num mesmo grupo pode prejudicar a sistematicidade da teoria, pois dificulta a caracterização dessas lexias enquanto classe de palavras. Ademais, a inclusão dos kyûchakugo com função adjetiva, considerados normalmente como auxiliares verbais (jodôshi), implicaria indubitavelmente na possibilidade de inclusão também de uma grande quantidade de outros auxiliares verbais, questão sobre a qual Sakuma evita discutir em sua obra.

\section{Considerações de Ide Itaru sobre Keishikimeishi (1967)}

Segundo a concepção de Ide Itaru, os keishikimeishi nunca formaram uma classe de palavras independente, sendo sempre incluídos dentro da classe dos substantivos (meishi), constituindo seu subgrupo.

Para Ide, os keishikimeishi pertencem a uma classe de palavras jamais delimitada claramente dentro dos estudos taxionômicos japoneses, ocupando um lugar marginal. Segundo ele, a peculiaridade das expressões da língua japonesa encontra-se justamente nas partes não abordadas pela classificação taxionômica japonesa, muito inspirada na gramática do Ocidente. Ide acredita que o keishikimeishi pertence à parte do léxico em 
que se pode observar claramente algumas das peculiaridades da língua japonesa. Daí a importância de se discutir e de se analisar sua natureza e suas funções dentro da frase, transpondo o mero nível taxionômico de investigação, afirma o teórico.

Ide identifica 121 keishikimeishi e os agrupa em doze tipos, tendo como critério de classificação o conteúdo semântico de cada um:

1) que exprime pessoa: hito "pessoa", mono "pessoa, gente" kata "pessoa (exprime polidez) etc.;

2) que exprime coisa: mono "coisa", bun "parte", hô "lado" etc.;

3) que exprime fatos: koto "fato" ten "ponto" yoshi "fato", tokoro "situação", shidai "situação" etc.;

4) que exprime tempo: toki "tempo ", ori "ocasião" baai "caso" sai "ocasião", aida (intervalo de tempo), setsu "ocasião", kan (intervalo de tempo), jibun "época", saichû "meio", sanaka "meio" tabi "vez" etc.;

5) que exprime lugares: tokoro/toko "lugar", atari "proximidade", hen "proximidade" soba "proximidade" uchi "espaço interno" saki "adiante" mae "frente" ushiro "atrás" ue "em cima" naka "dentro", shita "em baixo" etc.;

6) que exprime aparência ou estado: fû̀ "aspecto, estilo", bun "aspecto", tôri "jeito, maneira", furi "aparência", yôsu "aspecto" etc.;

7) que exprime intensidade: bakari "apenas, só", bun "parte", teido "grau" etc.;

8) que exprime propósito: tame "para";

9) que exprime causa ou motivo: wake "motivo", sei "(por) causa (de)", tame "causa" etc.;

10) que exprime intenção: tsumori "intenção", $k i$ "intenção", kangae "idéia" etc.;

11) que exprime probabilidade: hazu "probabilidade";

12) que exprime substituição: kawari "(no) lugar (de)".

A função do keishikimeishi, do ponto de vista de Ide, é demarcar a categoria semântica à qual pertence o conteúdo do modificador. Ide afirma ser insuficiente a definição tradicional simplista de keishikimeishi a qual o considera substantivo por ser um termo que requer sempre um modificador e que possui um conteúdo semântico abstrato; é necessário dizer que se tratam de lexias que convertem os modificadores em substantivos e que, ao mesmo tempo, definem a categoria (hanchû). Deduzimos que a "categoria", pelo contexto geral da obra desse autor, diz respeito à "categoria semântica" à qual os modificadores pertencem: por exemplo, mono "coisa" de yonda mono "coisa que leu", koto "fato" de yonda koto "o fato de ter lido" A "categoria", segundo Ide, relaciona-se às categorias ou áreas delimitadas de "pessoa" "fato" "objeto", "tempo" "lugar", "intensidade" e "causa":

Kono yôni, keishikimeishiwa, rentai shûshokusuru senkôno gokuno naiyôga ikanaru hanchûni zokusuru mononi tsuite nobeta monodearukao iisadamerutoiu hataraki, tsumari, hanchûo kiteisuru kinôo motsu monoto iwaneba naranai. [...] Kakute, keishikimeishiwa, ippanni bunpôshoni tokareteiru yôni, tsuneni rentai shûshokugoo hitsuyôtosuru meishide jisshitsuteki imiga chûshôtekina monodearu tonomi teigisurunodewa fujûbundeatte, mushiro sorewa, rentaishûshokusuru senkôno gokuo taigen shikakuno mononi tenkansuruto 
dôjini soreni itteino hanchûo ataeru kinôo motsu goshidearuto shinakereba naranainodearu (Ide: 1967:42-3).

Ide atribui ao keishikimeishi, não só a função sintática, mas também semântica, estabelecendo um elo sintático-semântico entre o modificador e o núcleo do sintagma nominal. De um lado, o keishikimeishi serve para nominalizar o modificador, e, de outro, serve para identificá-lo, se se trata de "pessoa" "objeto" "fato" explicitando a qual categoria ele pertence.

De forma geral, um substantivo da língua japonesa pode assumir diferentes funções sintáticas, com o auxílio de morfemas indicadores de caso ou de ênfase, mas os keishikimeishi abaixo mencionados sofrem restriçōes quanto às funções sintáticas que podem assumir:

- tôri "jeito, maneira", mama "estado", hakobi "estágio, ordenação";

- hodo "a ponto de", bakari "apenas, só", dake "só", kurai "só", kagiri "limite";

- tame "para";

- yue "causa", ageku "(no) final (de)" tame "causa";

- tsumori "intenção";

- hazu "probabilidade";

- kawari "(no) lugar (de)"

Tais keishikimeishi constróem predicados ou complementos verbais, mas dificilmente assumem a função de sujeito.

Ide ainda explica o motivo do caráter polissêmico de certos keishikimeishi: são lexias que originariamente expressavam um só campo semântico, mas que passaram a ter seu significado esvaziado, acompanhando a ampliação dos limites de seu campo semântico. A seguir, citamos exemplos referentes a mono e tokoro, apresentados pelo autor:

Sono ue sotokara shinnyûshitekuru monoo fuseganakerebanaranakatta. "Além do mais, era necessário impedir os (as pessoas) que nos invadiam de fora" (pessoa).

Omiyageni katte kita monoo kabankara hitotsu hitotsu toridashita. "Retirou da mala, uma a uma, as coisas que trouxera de presente" (coisa).

Ima watashino kangaeteiru tokorowa, ikanishite heionni jitaio shûshûsurukatoiu kotodearu. "O que estou pensando agora é como resolver a situação de maneira pacífica" (conteúdo).

Kô itta tokoroo hitoni mirareruto hazukashii. "Teria vergonha se me vissem nesse estado em que estou" (estado).

Machikutabirete kaerôto shita tokoroni yatte kita. "Chegou quando já estava cansado de esperar e prestes a ir embora" (tempo).

Nagaretsuita tokorowa chizunimo kakikomareteinai chippokena shimadatta. "O $\underline{\text { local onde }}$ cheguei naufragado era uma pequena ilha que nem constava do mapa" (lugar).

Segundo Ide, há um tipo de atenuação ou de esvaziamento de significado nos keishikimeishi, impossibilitando-os de expressar um único campo semântico. Esse processo de esvaziamento semântico explicaria também o seu papel na constituição de conjunções, tais como node "portanto" noni "apesar de", monoo "porém" tokoroga "no entanto" Etimologicamente, estas conjunções se originaram de keishikimeishi acompanhados de morfemas indicadores de caso (kakujoshi), mas, à medida que a carga 
semântica desses keishikimeishi se torna "vazia", os modificadores diminuem seu grau de dependência com o keishikimeishi, tornando-se autônomos, e os conjuntos formados por keishikimeishi e morfema gramatical transformam-se em conectivos.

Além desses conectivos, afirma o teórico, há na língua japonesa também os morfemas finais (shûjoshi) no, koto, mono/mon, cuja origem se encontra nos keishikimeishi e que tiveram suas cargas semânticas "esvaziadas" observando-se o processo de transformação de elementos nocionais em relacionais (de shi para ji). O esvaziamento semântico dos keishikimeishi propicia, de acordo com o teórico, a sua transformação em elementos relacionais, e é nesse sentido que se pode assinalar, de um lado, a proximidade desse grupo de lexias dos morfemas gramaticais em geral (joshi), ou melhor, dos elementos relacionais, e, por outro lado, a distância em relação aos substantivos, do quadro dos nocionais.

Observamos que Ide asssume um ponto de vista diferente de Yamada e Matsushita, quando define os keishikimeishi como elementos originariamente portadores de carga semântica delimitada que, com o tempo, sofrem um processo de esvaziamento semântico. Ide enfatiza, em sua teoria, o processo histórico de transformação das palavras, embora não chegue a explicitar os estágios dessas transformações. Acreditamos ser esta visão histórica uma das contribuições teóricas valiosas que Ide trouxe aos estudos do keishikimeishi. Além disso, Ide aprofunda as considerações tecidas por Sakuma, ao definir o keishikimeishi não só como um elemento substantivador, mas também como um definidor do tipo semântico de seu modificador. Entretanto, não é muito claro o relacionamento que ele estabelece entre a noção de "categoria" e o conteúdo de seu modificador, restando certa margem de dúvida.

Ainda Ide, com sua lista maior que as de seus predecessores, parece abarcar a maioria dos keishikimeishi apontados pelos mesmos, que nem sempre coincidiam quanto à delimitação desse grupo. Levando em consideração o caráter polissêmico de algumas lexias, Ide as situa em diferentes itens, contando assim mais de uma vez a lexia mono, uma no item que exprime pessoa, e outra no item que exprime coisa. São esses pontos que o distinguem substancialmente dos gramáticos precedentes.

\section{Outras considerações mais recentes}

Os trabalhos que encontramos após Ide mostram novos enfoques sobre os keishikimeishi, sobretudo do ponto de vista semântico-sintático. É o caso do teórico Teramura e de gramáticos gerativistas, como Okutsu. A partir deles, os estudos sobre a questão têm apresentado trabalhos bastante específicos que analisam um ou outro keishikimeishi em particular. Pela importância da visão inovadora que trazem sobre o keishikimeishi, procuramos sumariar nos itens subseqüentes as teorias de Teramura Hideo, Okutsu Keiichirô e Kudô Mayumi.

\section{Teramura Hideo (1974-8)}

É necessário ressaltar, em primeiro lugar, que Teramura tratou dos keishikimeishi como um grupo de lexias que apresenta uma determinada característica semântico- 
sintática dentro da estrutura gramatical japonesa, sem denominar a categoria em que se inclui.

Uma das preocupações de Teramura era a de analisar a "modificação nominal" da língua japonesa, isto é, os assim designados rentai shûshoku, e a relação entre o núcleo do sintagma nominal (SN) e seu modificador, dois componentes fundamentais dentro do SN. Desse ponto de vista, o gramático aponta as relações sintáticas e semânticas entre esses dois componentes, classificando-as em duas estruturas: a relação endocêntrica (uchino kankei) e a relação exocêntrica (sotono kankei).

Considerando que a ligação entre o núcleo [kodomo] "criança" e o modificador [gakkô-e iku] "ir à escola" do SN gakkôe iku kodomo "a criança que vai à escola" traz uma relação de sujeito e predicado, Teramura chamou-a de "endocêntrica" ou uchino kankei. Quando a relação entre esses dois componentes do sintagma não pressupõe a relação sintática sujeito/predicado, ou objeto/predicado de uma frase - como é o caso de gakkôe iku koto "o ato de ir à escola" - mas reflete apenas a relação núcleo (koto "fato, ato") /conteúdo detalhado ou especificação do núcleo (gakkôe iku "ir à escola"), é denominada por Teramura de relação exocêntrica ou sotono kankei.

Por esse ponto de vista, Teramura conclui que os chamados keishikimeishi constituem o núcleo do SN quando o modificador expressa seu conteúdo.

Apresentamos a seguir um exemplo onde se verifica a relação exocêntrica entre o modificador e o núcleo:

(a) Tanakasan-ga kekkonshita kotoo shitta. (Tanakasan-ga kekkonshita. Sono kotoo shitta).

"Soube do fato de o sr. Tanaka ter se casado/ Soube que o sr. Tanaka se casou" (O Sr. Tanaka se casou. Soube desse fato).

No exemplo (a), o segmento "Sr. Tanaka se casou" constitui o conteúdo ou a explicação detalhada do fato (koto).

Teramura explica que, diferentemente do SN que apresenta a estrutura endocêntrica, a estrutura da construção exocêntrica se caracteriza pela presença do modificador que expressa o conteúdo do núcleo. Em outras palavras, na concepção de Teramura, a especificidade semântica do núcleo do SN marca a estrutura exocêntrica. Dentre os substantivos que constituem o núcleo do $\mathrm{SN}$ nas construçōes exocêntricas, os keishikimeishi fazem parte dos mais abstratos quanto ao conteúdo semântico. Esses keishikimeishi são usados, de um lado, como conjunções e, de outro, como morfemas finais.

Teramura evita discutir a questão dessas lexias enquanto classe de palavras. Critica o fato do keishikimeishi ser comumente encarado como uma questão meramente taxionômica, afirmando que as definições e as explicações de seus empregos sejam demasiado conceituais (1978:04). Prefere observar a maneira pela qual os substantivos são empregados conforme suas especificidades semânticas, a tratá-los como um grupo taxionômico dos keishikimeishi. Dessa forma, espera poder observar seus fenômenos lingüísticos como uma questão sintática importante da língua japonesa, e não como uma mera questão taxionômica. 
Teramura ressalta a característica de certos substantivos - núcleos de $\mathrm{SN}$ - que, com a atenuação de seu significado substancial, tornam-se formais, perdendo o estatuto de substantivo. Divide-os, pois, de acordo com as diferentes funções sintáticas que desempenham (1978:02), classificando-os em substantivos com expressões de tempo, quantidade, intensidade, e também as de relatividade, como ue "em cima" shita "em baixo", mae "frente", nochi "depois", kekka "resultado" que têm caraterísticas adverbiais. Teramura seleciona as lexias, comumente consideradas keishikimeishi, que assumem função adverbial, com ou sem a posposição do morfema ni:

- toki, aida, koro, tabi, baai, tame, yue, kekka, sue, ageku, ue, amari, tokoro, kurai, mama, tôri, kagiri.

As mesmas lexias podem transformar-se em conectivos que ligam as orações (setsujoshika), e também em expressões de modalidade, quando surgidas no final da oração (bunmatsu jodôshika), juntamente com expressões como o auxiliar verbal da de afirmação, verbos como aru "haver", suru "fazer", naru "tornar-se", além de nai "não haver" Assim, as lexias tsumori, hazu, wake, yôsu, ki, hô e outros, que se juntam a da (afirmação), ga-aru/nai (experiência), ga/o-suru (ação), ga-ii (preferência), formam as expressões:

- tsumori-da "tenho a intenção de", hazu-da "deve (suposição)" wake-da (motivo), mono-da "deve (sugestão), tokoro-da (iminência), yoshi-da (alusão);

- koto-ga aru (experiência), kai-ga aru "vale a pena";

- ki-ga suru "ter a impressão de" kanji-ga suru "ter a impressão de" mane-o suru "imitar";

- hô-ga ii "é melhor"

Para Teramura, as expressões acima indicam a atitude do falante em relação ao conteúdo proposicional da frase.

Teramura estuda as características dessas lexias, definindo-as como sendo "multifuncionais" (takakuteki kinôo motsu). O teórico se propõe a analisar especificamente algumas que apresentam maior complexidade, entre elas koto e mono.

$\mathrm{Na}$ descrição de koto, Teramura distingue quatro diferentes empregos:

1) como substantivo propriamente dito (jisshitsumeishi), que permite fazer parte da estrutura endocêntrica;

2) como substantivo que requer um modificador, na estrutura exocêntrica.

(Ex.: Tôgorôga korobude-arôtoiu kotowa... "O fato de que possivelmente Tôgorô vá renunciar à sua fé...");

3) como conjunção (Ex.: Odoroita kotoni... "Para minha surpresa..." Oshôgatsuno kototote... "Uma vez que é Ano Novo...")

4) como auxiliar verbal (jodôshi), no final da oração (Ex.:

...[suru] koto-ga dekiru "Sabe fazer..."

...[suru] koto-ni suru "Faz de conta que...",

...[suru] koto-ni naru "Foi resolvido que..."

...[suru/shita] koto-ga aru "Há vezes que.../Tem a experiência de..."

...koto-da "Deve...").

OTA, Junko. A Tradição Histórica dos Estudos de Keishikimeishi. 
$\mathrm{Na}$ análise do keishikimeishi mono, Teramura distingue três empregos:

1) utilizado como substantivo com conteúdo semântico substancial. Retomando a afirmação de Matsushita, que considerou mono "coisa" como substantivo com conteúdo substancial, e mono "pessoa" como keishikimeishi, Teramura afirma que mesmo no emprego de mono "coisa", são constatados significados dos mais concretos ex. (a) ou mais abstratos ${ }^{9}$ ex. (b):

(a) Omaega hoshii monoo yarô. "Darei o (a coisa) que você quiser"

(b) Bundannadoto iu monowa, jinseino mondaimo geijutsu-no mondaimo kesshite kaiketsushitekureru tokorodewa arimasen. (Nakamura Mitsuo, de Waraino sôshitsu) "(A coisa chamada) O chamado círculo literário não é um lugar onde se resolvem problemas da vida nem da arte"

O mono do ex. (a) é definido por Teramura como expressão de um objeto concreto, palpável, com forma, enquanto que do ex. (b) é considerado expressão da existência (jittai), nesse caso, de uma organização social chamada "círculo literário", mas há também empregos em que mono expressa a essência (honshô), como em 3), que apresentamos mais adiante.

2) utilizado como conjunção acompanhado de auxiliares verbais, tornando-se monono "embora" monoo "no entanto", monodakara "portanto"

3) empregado no final da frase, como auxiliar verbal. Expressa essência ou natureza; sugestão; circunstância; emoção diante da lembrança do passado ou surpresa ante uma constatação no presente.

Observamos que Teramura enfoca a questão da estrutura de modificação nominal, em que o keishikimeishi ocupa um lugar específico. Teramura caracteriza esses termos como "possuidores de significados abstratos" "portadores de um campo semântico amplo" "complexos" e "possuidores cada qual de seu próprio uso, de seu domínio" Seu trabalho constitui ainda hoje um estudo dos mais aprofundados e abrangentes a respeito das lexias keishikimeishi. Com relação a lexias que analisou detalhadamente, Teramura estuda suas funções desempenhadas dentro da oração: função adverbial, conectiva e modal. Contudo, o teórico não chega a analisar em profundidade sua relação com o modificador.

\section{Okutsu Keiichirô (1974)}

A estrutura da relação exocêntrica (sotono kankei) proposta por Teramura foi denominada, por Okutsu Keiichirô (1974), de "estrutura da modificação adicional do nome", fuka rentai shûshoku kôzô, dentro de uma perspectiva gerativista. Para demonstrar tal estrutura, Okutsu cita exemplos que contêm as lexias koto "fato, ato", mae "antes" e ato "depois", cuja relação com o keishikimeishi parece ser evidente. Entretanto, o grupo

9. Estamos traduzindo jisshitsuteki como concreto e keishikiteki como abstrato. Para Teramura, jisshitsuteki significa material e real, como é o caso do "objeto que você quer" e keishikiteki, o que não é palpável fisicamente, como "círculo literário" 
de lexias a que temos denominado keishikimeishi é considerado por Okutsu uma classificação desnecessária.

Okutsu aponta que os teóricos precedentes eram unânimes em afirmar o caráter dependente das lexias pertencentes ao grupo de keishikimeishi que, em função de sua característica de conteúdo semântico abstrato, surgem acompanhadas de algum modificador. Afirma, entretanto, que a maioria dos keishikimeishi não exige obrigatoriamente um modificador, e cita como exemplo as lexias hito "pessoa", mono "coisa", toki "tempo" e tokoro "lugar". Com essa argumentação, afirma que a necessidade de um modificador não serve de parâmetro para decidir se uma lexia é ou não um keishikimeishi.

Outro ponto criticado por Okutsu é a afirmação de que o keishikimeishi requer um modificador por seu conteúdo semântico ser abstrato:

[...] Dizem que os keishikimeishi requerem um modificador porque seu referente é abstrato. Porém, o que seria o 'caráter abstrato' do referente de um substantivo? Poder-se-ia considerar o grau de abstração como critério de classificação entre um keishikimeishi e um não-keishikimeishi? [...] Onde começa e onde termina o keishikimeishi? [...] Não há um critério que possa dividir os substantivos em dois, de acordo com o grau de abstração (Okutsu, 1974:205).

Considerando o substantivo hito "pessoa" um representante de keishikimeishi, o teórico afirma que há substantivos mais abstratos, tais como dôbutsu "ser animal", seibutsu "ser vivo" e sonzai "existência" que, não obstante, não são incluídos dentro do grupo dos keishikimeishi. Okutsu considera que o grau de abstração do conteúdo semântico de um substantivo é relativo, podendo, assim, apenas afirmar-se que um substantivo é mais ou menos abstrato que o outro. E entre os substantivos mais abstratos e os mais concretos há inúmeras camadas intermediárias, não classificáveis. É por isso que, na opinião de Okutsu, cada teórico conta e classifica de maneira diferente e variada os keishikimeishi. O autor afirma não haver característica dicotômica entre os keishikimeishi e os não-keishikimeishi, justificando assim a não necessidade dessa classificação com o nome de keishikimeishi.

Concordamos com Okutsu quanto à questão da descrição do keishikimeishi. A crítica quanto à imprecisão na definição desse grupo de lexias, feita por Okutsu, é procedente, e os critérios de classificação e de subdivisão realmente têm oscilado muito de um teórico a outro. Porém, sendo "uma das funções essenciais das classes de formas (por exemplo, das classes de palavras) justamente permitir a descrição compacta do comportamento sintático das formas", como afirma Perini (1989:37), com quem concordamos, acreditamos que as descrições dos keishikimeishi propostas pelos teóricos precedentes são válidas, e não só isso, são úteis para a descrição das lexias que apresentam certos comportamentos sintáticos e semânticos em comum.

Acrescentamos, ainda, que o exemplo hito "pessoa" que Okutsu define como "keishikimeishi representativo, citado na maioria dos casos", não é unanimidade entre os teóricos, podendo ser encontrado somente nas classificações de Sakuma e Ide. 


\section{Kudô Mayumi (1985)}

Kudô não chega a fazer considerações sobre o keishikimeishi em si, mas analisa uma parte da composição sintagmática que envolve o koto. Seu trabalho tem como enfoque os empregos de no e koto nos sintagmas nominais e sua relação com os tipos de verbos da oração principal (1985). Considerando koto como elemento nominalizador, no exemplo:

Sofu- ga shinda koto- o hanasu,

avô SUJEITO morreu fato O.D. contar

"Conto que meu avô faleceu",

Kudô afirma que a expressão sofu-ga shinda "meu avô faleceu" é nominalizada pelo koto "fato"

De acordo com Kudô, os verbos que aceitam koto como complemento direto (objeto direto) são:

a) os relacionados a atos de pensamento, tais como omou "achar, pensar", kangaeru "pensar", shinjiru "acreditar", utagau "duvidar" rikaisuru "compreender";

b) os relacionados a atividades comunicativas, tais como iu "dizer" hanasu "falar", kiku "ouvir", kaku "escrever", shiraseru "avisar", tsutaeru "comunicar";

c) os relacionados a atividades voluntárias (exigência, proibição, permissão, desejo, determinação), tais como meijiru "ordenar", susumeru "sugerir", kinjiru "proibir", yurusu "permitir", nozomu "desejar", kimeru "decidir", yakusokusuru "prometer"

d) os relacionados a atividades de indicação, tais como shimesu "indicar" sasu "apontar", shômeisuru "provar" honomekasu "insinuar, dar a entender"

Como correlatos das atividades de pensamento e de comunicação, os verbos que expressam percepção ou cognição também podem ter os complementos com o keishikimeishi koto, ou então no:

- hakkensuru "descobrir", kanjiru "sentir", shiru "saber", wakaru "perceber, dar conta", kizuku "notar", oboeru "aprender" omoidasu "lembrar"

Há, ainda, outros verbos que podem ser englobados nessa categoria: são os verbos que expressam a atitude do sujeito em relação ao objeto. Essa atitude pode ser valorativa, como se pode observar nos verbos:

- yorokobu "ficar contente", kanashimu "ficar triste", odoroku "surpreender", kitaisuru "esperar com expectativa", sanseisuru "concordar", hiteisuru "negar"

Outros verbos que também têm o koto como complemento, são:

- yameru "parar", yosu "deixar, parar", sakeru "esquivar", fusegu "evitar"

Kudô caracteriza tais verbos, de modo geral, como "verbos que exprimem atividades cognitivas (chiteki katsudô)" Acreditamos que o levantamento e a análise de koto realizados por Kudô são de grande valia para caracterizar o keishikimeishi koto. A abrangência de sua análise, porém, parece-nos bastante limitada, uma vez que seu intuito era fazer a comparação entre os keishikimeishi koto e no, relacionando-os com 
os verbos da oração principal, e não analisar o funcionamento do keishikimeishi koto em si. Portanto, o enfoque de Kudô com relação a koto se aplica a uma parcela de seu emprego, deixando muitas outras a serem analisadas.

É importante salientar, aqui, que as teorias comentadas neste artigo merecem estudos e análises aprofundadas ainda nos nossos tempos, para a compreensão do trajeto histórico de estudos da língua japonesa.

\section{Bibliografia}

HASHIMOTO, Shinkichi. "Kokugohô yôsetsu" ("Considerações Essenciais da Gramática Japonesa"), in Kokugohô Kenkyût (Pesquisas da Gramática Japonesa). 15" ed., Tokyo, Iwanami, 1968 (1ª ed. 1948).

. Kokubunpô taikeiron (Teoria dos Sistemas Gramaticais da Língua Japonesa). Tokyo, Iwanami, 1967 ( $1^{\text {a }}$ ed. 1959).

IDE, Itaru. "Keishikimeishitowa nanika" ("O que é keishikimeishi"), in Kôza Nihongono bunpô 3 - hinshikakuron (Coleção Gramática da Língua Japonesa 3 - Considerações Sobre a Taxionomia). Tokyo, Meiji Shoin, 1967.

KuDô, Mayumi. "Koto, nono tsukaiwaketo dôshino shurui" ("A diferencição de emprego do koto e no e os tipos de verbos"), in Kokubungaku kishakuto kanshô 3 (Interpretação e Apreciação da Literatura Japonesa 3). Tokyo, Shibundo, 198.5.

MaTSUSHITA, Daizaburo. Kaisen hyôjun nihon bunpô (A Gramática Japonesa Normativa Reexaminada). Tokyo, Kigensha, 1928.

Hyôjun nihon bunpô (A Gramática Normativa da Língua Japonesa). Tokyo, Kigensha, 1930.

OKUTSU, Keiichirô. Seisei nihon bunpôron (Teoria da Gramática Gerativa Japonesa). Taishukan, 1974.

SAKUMA, Kanae. Gendai nihongono hyôgento gohô (As Expressōes e Regras Gramaticais da Língua Japonesa Contemporânea). Tokyo, Koseisha Koseikaku, 1966 (1' ed. Em 1936 e revista em 1951).

. Gendai nihongo hôno kenkyûu (Estudos de Regras Gramaticais do Japonês Moderno). 5" ed., Tokyo, Kôseisha Kôseikaku (1" ed. revista em 1952).

Teramura, Hideo. "Nihongo meishino kai bunrui" "A Subclassificação dos Substantivos em Japonês"), in Nihongo Kyôsiku. V.12. Tokyo, Nihongo Kyôiku Gakkai, 1968.

"Rentai shûshokuno shintakkusuto imi - sono 1-4" ("A Sintaxe e Significado da Determinação Nominal - 1-4"), in Nihongo, nihonbunka. No.7, Osaka, Osaka Gaidai Ryûgakusei Bekka, 1974-78.

TOKIEDA, Motoki. Kokugogaku genron (Princípios da Gramática da Língua Japonesa). 36ª ed., Tokyo, Iwanami (1" ed. 1941). . Nihon bunpô - kôgohen (Gramática Japonesa - Série Língua Falada). Tokyo, Iwanami Shoten, 1968 (1" ed. 1950).

Nihon bunpô - bungo hen (Gramática Japonesa - Série Língua Clássica). $24^{\mathrm{a}}$ ed., Tokyo, Iwanami, 1979.

YAMADA, Yoshio. Nihon bunpôron (Teoria Gramatical do Japão). Tokyo, Hôbunkan, 1908. Nihon bunpôgaku gairon (Considerações Gerais de Estudos Gramaticais do Japão). Tokyo, Hôbunkan, 1936.

Centro de Estudos Japoneses da USP - Curso de Língua e Literatura Japonesa 